\title{
"Can You Remember What Was in Your Pocket When You Were Stung by a Bee?": Eliciting Cues to Deception by Asking the Unanticipated
}

\author{
Meiling Liu ${ }^{1}$, Pär Anders Granhag ${ }^{2}$, Sara Landström² ${ }^{2}$ Emma Roos af Hjelmsäter ${ }^{2}$, Leif Strömwall ${ }^{*}, 2$ \\ and Aldert Vrij ${ }^{3}$
}

\author{
${ }^{I}$ Department of Humanity and Social Sciences, Inner Mongolia Agricultural University, China \\ ${ }^{2}$ Department of Psychology, University of Gothenburg, Sweden \\ ${ }^{3}$ Department of Psychology, University of Portsmouth, UK
}

\begin{abstract}
In this paper we focused on children's deception (10-12 years, Experiment 1), and adult's ability detect deception in children (Experiment 2). The self-presentational perspective (DePaulo, 1992) suggests that both liars and truth tellers will try to act in a convincing manner to be assessed as truth tellers. By asking unanticipated questions we put the liars in the following dilemma: If they did not answer they would risk being considered avoidant and, thus, run the risk of being discredited. On the other hand, if they did answer they would risk failing to act like a truth teller, and thereby run the risk of being discredited. In Experiment 1 we predicted, and found, that liars' attempt to actively create an honest impression (answer) overruled their attempt to passively imitate truth tellers (not answering). Specifically, liars (vs truth tellers) were more willing to answer the unanticipated questions. Experiment 2 showed that adult observers had difficulty when discriminating between lying and truth-telling children (overall accuracy rate: 57\%). Lie-catchers who had been exposed to children answering unanticipated questions did not outperform lie-catchers who had watched children answering anticipated questions. Our successful attempt to elicit a diagnostic cue to deception (willingness to answer unanticipated questions) is placed within the new line of research aimed at increasing lie-catchers' ability to detect deception.
\end{abstract}

Keywords: Children's deception, unanticipated questions, cues to deception, deception detection.

\section{INTRODUCTION}

Being able to correctly assess the veracity of statements offered by suspects, witnesses and alleged victims is of utmost importance in legal settings. Today there is a large body of research on humans' deception detection ability, and the research literature to a large extent focuses on liecatchers' often unsuccessful strategies (Vrij, 2008). However, more recently, several scholars address the question of how to best interview in order to discriminate between liars and truth tellers. This line of research investigates how to interview to elicit diagnostic cues to deception and truth, and thereby increase lie-catchers' ability to detect deception. The present paper is part of this new line of constructive research. Specifically, the paper examines the effects of asking unanticipated questions during an interview, and - as will be further outlined below - our main prediction is that liars and truth tellers will answer such unanticipated questions differently.

The vast majority of the deception research conducted so far is on adult's ability to detect adult's deception. The current paper, however, focuses on children's deception (Experiment 1), and adult's ability to detect children's deception (Experiment 2). Investigating children's strategies

*Address correspondence to this author at the Department of Psychology, University of Gothenburg, P.O. Box 500, SE40530, Sweden; Tel: +46 31

786 1665; Fax: +46 31786 4628; E-mail: leif.stromwall@psy.gu.se when lying and telling the truth, as well adults' ability to detect children's deceptive attempt, are important areas for research for several reasons. First, it is important in situations where a child is accusing an adult (or a peer child), and when there is a need to scrutinize if this accusation is correct. Second, a child can be under suspicion of many forms of wrongdoings. At most times the incident might be rather minor (e.g., eating candy when not allowed), at other times, however, the event under investigation is much more serious (e.g., allegedly having harmed another child). Hence, in some situations the stakes are very high, and it becomes crucial to correctly assess the veracity of the child's statement.

\section{LIARS' AND TRUTH TELLERS' VERBAL STRATEGIES}

The research on liars' and truth tellers' strategies is scarce. However, the so-called self-presentational perspective presented by Bella DePaulo (1992) offers an interesting theoretical angle by advocating that liars and truth tellers have a mutual goal: To appear honest. The major difference between liars and truth tellers is, of course, that only a truth teller has grounds for his or her claim, as a liar's claim to be honest is false. Differently put, liars need to act as truth tellers, and they can not (like truth tellers) take for granted that they will be assessed as telling the truth (Kassin, 2005). Hence, liars must plan in advance, or decide on the spot, how to best escape the lie-catcher's critical eye. Indeed, research has shown that liars plan their behavior to a higher extent than truth tellers (Hartwig, Granhag, \& Strömwall, 
2007). Moreover, research on adult mock suspects' verbal strategies shows that liars report to try to avoid giving a too detailed testimony, and that truth tellers report to try to talk in a spontaneous manner (Granhag \& Strömwall, 2002). Other research has shown that liars reported to have tried to keep their story simple, whereas truth tellers reported to have tried to keep their story real (Strömwall, Hartwig, \& Granhag, 2006). For a similar pattern of results, see Hartwig and colleagues (2007).

Even less research has been carried out with respect to lying and truth-telling children's strategies. One study found that lying children (age 11-13) reported to have tried to appear honest by keeping the story simple, whereas truthtelling children reported to simply having told the story like it happened (Strömwall, Granhag, \& Landström, 2007). These findings are in alignment with research on adult suspects showing that liars tend to provide shorter answers than truth tellers (Vrij, 2008).

Research regarding the psychology of guilt and innocence shows that guilty suspects' planning of a future interview can be framed in terms of self-regulation theory. This theory focuses on processes aimed at directing a person towards a goal or away from a looming threat (Fiske \& Taylor, 2008). The pathways to reach the desired state are labelled control strategies, and it has been argued that one such form - decision control - is of particular relevance for interrogative settings (Granhag \& Hartwig, 2008). In the current context, decision control aims at reducing threat by deciding on how to act during the interrogation (e.g., what to admit, avoid and deny). Self-regulation theory broadly predicts that liars will employ various strategies to achieve their goal of being believed (for a more detailed account, see Granhag \& Hartwig, 2008). In contrast, innocent suspects' planning (decision control) is predicted to be coloured by basic psychological concepts such as the belief in a just world (i.e., one gets what one deserves, and deserves what one gets, Lerner, 1980) and the illusion of transparency (i.e., the belief that one's inner feelings/states will manifest themselves on the outside, Savitsky \& Gilovich, 2003). Therefore, innocent suspects will plan what to say during an interview to a much lesser extent than guilty suspects. See Kassin (2005) for a discussion about how innocent suspects may put themselves at risk by taking their innocence for granted.

\section{THE UNANTICIPATED QUESTION APPROACH}

A rather uncontroversial claim is that a lie-catcher's success is predicted by the extent to which he or she is able to read the strategies used by the suspect under investigation. Only recently have researchers started to examine how interviews should be carried out to facilitate lie detection (Granhag \& Vrij, 2010). These approaches are theoretically driven (e.g., the cognitive load approach, Vrij, Fisher, Mann $\&$ Leal, 2006, and the strategic use of evidence approach, Granhag \& Hartwig, 2008), and take the strategies used by truth tellers and liars into account. In the present paper we will highlight a different approach, which we label the unanticipated question approach.

The reasoning behind the unanticipated question approach is as follows: Liars (more than truth tellers) are assumed to plan what to say during the upcoming interview.
That is, liars will think of questions that will be asked, and will prepare answers to these questions. However, if liars are asked questions which they have not anticipated, they face a difficult task for several different reasons. For example, it can (a) place the liar in an awkward position with respect to what he/she has agreed with their partners in crime to say during the interview (Vrij et al., 2009), or (b) require a retelling procedure not prepared in advance (e.g., to tell the story in backwards order, see Vrij et al., 2008).

In the present paper we will introduce yet another form of unanticipated questions. We selected questions which were thought to be difficult, but not impossible, to answer. The questions selected were peripheral to the event under examination; hence, neither liars nor truth tellers would run the risk of incriminating themselves by answering these unanticipated questions. Nevertheless, according to our reasoning, these questions would place the liar in a rather difficult dilemma, where he/she must consider the consequences of answering versus not answering these unanticipated questions. Specifically, by not answering he/she might be viewed as avoidant (and thereby evoke suspicion), but by answering he/she might fail to respond as a truth teller would do (and thereby evoke suspicion).

We believe that a liar's intention to actively behave in a convincing manner (e.g., try to answer difficult questions) will overrule his/her attempts to act like a truth teller. The reason for this is that whereas it is relatively easy to imitate truth tellers when having prepared what to say, it is a much more difficult task to do this on the spot. A liar faced with the dilemma whether or not to answer a difficult question (due to difficulties in predicting how a truth teller would have acted in the same situation), is expected to be tipped in the direction of answering the question. By not answering the question he/she will run the risk of failing both with respect to (a) appearing honest and (b) properly imitate a truth teller. By answering the question, he/she will 'only' run the risk of failing with respect to properly imitating a truth teller.

Another reason why liars may be more willing than truth tellers to answer difficult questions, is that people tend to rate the accuracy of their own memories and other peoples' memories differently (Crombag, Merckelbach \& Elffers, 2000). In our deception context, this may result in liars overestimating the memory performance of truth tellers. Hence, liars run the risk of being more willing to answer difficult questions than are truth tellers.

\section{EXPERIMENT 1}

In Experiment 1, 46 children told the truth about a selfexperienced event and 46 children lied about an event. Half of the truthful and half of the lying children were asked a set of anticipated questions (e.g., 'where did this event take place?'), and the remaining two halves were asked a set of unanticipated questions (e.g., 'what did it smell like at the location where the event took place?'). The first aim of the experiment was to examine whether lying children planned their verbal and nonverbal behavior more than truth-telling children. The second aim was to examine possible differences with respect to lying and truth-telling children's willingness to answer unanticipated questions. 
Based on the psychology of guilt and innocence (Granhag \& Hartwig, 2008; Kassin, 2005), and previous findings on children's strategies (Strömwall et al., 2007), we predicted that lying children would report having planned their verbal (Hypotheses 1a) and nonverbal behavior (Hypotheses 1b) before the interview to a higher degree than truth-telling children.

Furthermore, with reference to the self-presentational perspective (DePaulo, 1992), and our reasoning above, we predicted that liars and truth tellers combined would be more willing to answer anticipated than unanticipated questions (Hypothesis 2a). In addition, we expected a difference between liars and truth tellers with respect to question type. Specifically, we predicted that the lying children would show more willingness to answer the unanticipated questions than the truth-telling children (Hypothesis 2b). No such difference was expected for the anticipated questions.

In terms of the response length (as measured by number of words), we predicted that for the unanticipated questions the liars' answers would be longer than the truth tellers' answers (Hypothesis 3a). For the anticipated questions we predicted the opposite pattern: The truth tellers' answers would be longer than the liars' answers (Hypothesis $3 b$ ).

\section{METHOD}

\section{Participants}

In total 92 children (10-12 years old, 48 girls and 44 boys) participated in the study. The children were recruited from local schools in Gothenburg (Sweden) and we collected oral consent from the children, and written consent from the children's parents and teachers.

\section{Procedure}

All children initially answered a so-called Life Event Inventory, which was originally designed and used by Strömwall and colleagues (2007). The inventory consists of a list of 13 events, each event listed is moderately emotionally charged in order to increase the chance that the child will remember whether or not he or she has experienced any of the events listed (e.g., "Can you remember an occasion when you squeezed a finger?). We thought it to be likely that each child in this particular age group would have experienced one or several of the events. Each child worked through the 13 events individually. For each event the child was asked to, truthfully, mark 'yes' (I have experienced such an event) or 'no' (I have not experienced such an event).

Next, all children were informed that they were to be interviewed, individually, about one particular event from the questionnaire. One group $(N=46)$ was instructed that they would be interviewed about one event that they had reported to have experienced, and they were asked to answer the forthcoming questions asked about this event in a truthful manner. The other group $(N=46)$ was informed that they would be interviewed about an event that they had marked with a 'no' in the questionnaire. That is, an event that they had not experienced. They were asked to answer all questions about this particular event as having really experienced the event (i.e., they were asked to lie). Finally, each child was informed about which particular event he or she was going to be interviewed about (different events for different children), and each child was given three minutes to prepare before the interview.

Three persons, with experience in interviewing children, conducted the interviews. They did not know whether the child was lying or telling the truth. First, the interviewers introduced themselves, invited the child to sit down, and explained the purpose of the interview. Next, they asked a predefined set of questions, following a structured interview. Two different sets of questions were used; one set included six anticipated questions, and the second set included six unanticipated questions (see Appendix 1). Each child was only exposed to one of the two sets of questions. The anticipated questions were event-relevant (e.g., "Where did this event take place?"), whereas the unanticipated questions were event-irrelevant (e.g., "What did you have in your pockets when this happened?"). We used a between-subjects design. Half of the 92 children were lying and half were telling the truth; half of the lying $(N=23)$ and half of the truth-telling children $(N=23)$ were asked anticipated questions, whereas the remaining lying and truth-telling children were asked unanticipated questions. All interviews were videotaped and then transcribed. The transcripts were used to analyze children's willingness to answer the questions and to calculate response length. Since the children answered a different number of questions, we divided the total number of words in the children's answers by the number of questions answered to obtain the dependent variable.

\section{Questionnaire}

After the interview, each child was asked to fill out a short questionnaire. They first reported their gender and age. They were then asked to rate the extent to which they had prepared their verbal statement and nonverbal behavior on six point-scales ranging from 1 (not at all) to 6 (very much).

\section{RESULTS}

\section{Children's Planning}

In alignment with Hypothesis 1a we found that lying children reported to have planned their statements to a higher extent $(M=2.59, S D=1.26)$ than truth-telling children $(M=$ $1.84, S D=0.95), t(89)=3.17, p<.01$. There was no difference in the planning of nonverbal behavior between liars $(M=1.46, S D=1.03)$ and truth tellers $(M=1.39, S D=$ $0.75), t(88)=0.37, p=.71$. Thus, Hypothesis $1 \mathrm{~b}$ was not supported.

\section{The Children's Willingness to Answer the Questions}

Despite most children attempting to answer all questions, they answered more anticipated questions $(M=5.63, S D=$ $0.57)$ than unanticipated questions $(M=5.17, S D=0.97)$, Welch's $t(72.77)=2.74, p<.01$, one-tailed. Hypothesis $2 \mathrm{a}$ thus received support. Moreover, the lying children $(M=$ $5.43, S D=0.79$ ) answered the unanticipated questions significantly more often than the truthful children $(M=4.91$, $S D=1.08), t(44)=-1.87, p<.05$ (one-tailed), thereby supporting Hypothesis $2 \mathrm{~b}$. The anticipated questions were answered as often by truthful $(M=5.57, S D=0.66)$ and deceptive children $(M=5.70, S D=0.47), t(44)=0.77, p=$ .45 . 


\section{Response Length}

To examine differences in children's response length (as measured by the mean number of words in the answers to the interview questions), two independent samples $t$-tests were conducted. First, we found that for the unanticipated questions, the deceptive children's answers $(M=8.70, S D=$ 4.26) were longer than the truthful children's answers $(M=$ 7.04, $S D=5.06)$, however the difference was not significant $t(44)=-1.21, p=.12$ (one-tailed). A non-significant tendency in the predicted direction was also found for the anticipated questions: truthful children' $(M=14.22, S D=$ $8.83)$ was longer than the deceptive children's answers $(M=$ $11.50, S D=7.68), t(44)=1.12, p=.14$ (one-tailed). The combined results show partial support of Hypotheses 3a and $3 b$.

\section{EXPERIMENT 2}

Experiment 1 showed that lying children (a) reported to have planned their statement more extensively than truthtelling children, and (b) were more willing to answer unanticipated questions than were the truth-telling children. Experiment 2 focused on adults' ability to detect children's deception. Research has shown that adults' ability to discriminate between children's truthful and deceptive accounts is mediocre, with accuracy rates just above the level of chance (Vrij, 2008). Research has also shown that adults tend to assess children's statements as truthful rather than deceptive. A consequence of this so-called truth bias is that lie-catchers are somewhat better at detecting truthful than deceptive statements (e.g., Strömwall \& Granhag, 2005; Westcott, Davies, \& Clifford, 1991).

The major aim of Experiment 2 was to examine adult liecatchers ability to discriminate between the children's truthful and deceptive accounts. In line with previous research we predicted that the adult's overall deception detection accuracy would be poor (Hypothesis 1a), and that the adults would exhibit a truth bias (Hypothesis 1b). In addition, we tested the effect of question type (unanticipated or anticipated questions) on deception detection accuracy.

\section{METHOD}

\section{Participants}

A total of 92 undergraduate students (57 women, 35 men) from the University of Gothenburg participated in the experiment. Their age ranged from 17 to 39 years $(M=$ 24.32, $S D=4.27$ ), and they were guaranteed a payment equivalent to $25 \mathrm{SEK}$ (approximately $3 \mathrm{USD}$ ).

\section{Materials and Procedure}

We used the videotaped interviews from Experiment 1. The videotapes showed full images of both the interviewer and the child. Each observer watched one videotaped interview, and assessed one child. Prior to watching the videotape each observer was given an information sheet stating that he or she was going to watch an interview with a child, and that he or she had to assess the veracity of the child's statement. They were also instructed that it was as likely that the child was lying as it was that the child was telling the truth. The observers were not informed about the different set of questions used. That is, that half of the children were asked anticipated questions and that the other half was asked unanticipated questions. After watching the videotape the observers made a dichotomous veracity judgment (the child told the truth/the child lied). In addition, they were asked to rate the extent to which they perceived the questions asked as unusual, on a scale from 1 (not at all) to 7 (very much).

\section{RESULTS}

\section{Manipulation Check}

An independent $t$-test showed that the observers rated the unanticipated questions $(M=4.26, S D=1.64)$ as significantly more unusual than the anticipated questions $(M$ $=2.20, S D=1.26), t(90)=6.78, p<.001$, which shows that the manipulation of anticipated and unanticipated questions was successful.

\section{Veracity Assessments}

Overall, the observers' accuracy rate was $57.6 \%$, which was not significantly better than chance level (binominal $p=$ .18). Hence, Hypothesis 1a was supported. Separate analyses showed that the observers in the anticipated question condition obtained an accuracy rate of $56.5 \%$, and the observers in the unanticipated question condition showed an accuracy rate of $58.7 \%$. The two conditions did not differ significantly, $\chi^{2}(1, N=92)=0.05, p=.83$.

\section{Judgment Bias}

In contrast to Hypothesis $1 \mathrm{~b}$ (stating that the observers would exhibit a truth bias) the observers made more lie judgments than truth judgments $(62 \%$ and $38 \%$, respectively). That is, overall the observers showed a significant lie bias (binomial $p<.05$ ). Separate analyses showed that the observers who had watched children answering anticipated questions made significantly more lie judgments $(67.4 \%)$ than truth judgments $(32.6 \%)$, (binomial $p<.05)$. In contrast, the observers who had watched children answering unanticipated questions did not show a significant judgment bias (binomial $p=.46$ ).

\section{DISCUSSION}

We examined whether lying children would be more willing than truth-telling children to try to answer unanticipated questions during an interview. In addition, we investigated whether adult observers would be able to discriminate between children's truthful and deceptive accounts differently when assessing anticipated questions than when assessing unanticipated questions. Below we discuss each of these issues in more detail.

\section{Children's Performance}

Overall, truth tellers and liars combined answered, in alignment with our hypothesis, significantly more anticipated questions than unanticipated questions. The results of Experiment 1 also supported our main hypothesis, that lying children would be more willing than truth-telling children to answer unanticipated questions. Furthermore, we found no such difference in terms of truth tellers' and liars' willingness to answer anticipated questions. The essential finding here is that we, by our choice of questions, were able to elicit a cue to deception. 
It is interesting to note that this finding relates to Criterion 15 of Criteria-Based Content-Analysis (CBCA, Köhnken, 2004). CBCA is an important component of the Statement Validity Assessment (SVA), which is one of the more common verbal content techniques for assessing the veracity of statements (Vrij, 2008). Criterion 15 predicts that truth tellers (more often than liars) admit lack of memory.

Furthermore, we predicted and found that lying children planned their verbal behavior more extensively than truth tellers. This finding fits nicely with current theoretical reasoning (Granhag \& Hartwig, 2008; Kassin, 2005) and empirical findings (Hartwig et al., 2007), on the psychology of guilt and innocence.

\section{Adult Lie-Catchers' Performance}

The overall result of Experiment 2 showed that adult liecatchers were poor at discriminating between lying and truth-telling children. This is a typical finding in deception research (Vrij, 2008). Our results further show that adults watching children answering unanticipated questions did not outperform adults watching children answering anticipated questions. The reason why question type did not affect accuracy should probably not be attributed to adults not noticing any difference between unanticipated and anticipated questions (our manipulation check revealed that they perceived the unanticipated questions as more unusual). Instead, we can think of three reasons as to why question type had no impact on the lie-catchers' total accuracy rate. First, our lie-catchers were not told that willingness to answer difficult questions might be a diagnostic cue to deception. Second, each adult lie-catcher watched only one child. Consequently, our lie-catchers had no opportunity to compare different children's different willingness to answer. Third, the diagnostic cue was difficult to spot, as the objective difference between lying and truth-telling children's willingness to answer anticipated and unanticipated questions were rather small.

In contrast to previous research (Strömwall et al., 2007) we did not found a truth bias among the adult lie-catchers; instead, a lie bias in the anticipated questions condition was found. A possible explanation for this lie bias is many truthtelling children were asked to talk about events that dated far back in time. It might be that the lie-catchers were too quick in discrediting the children for not being able to provide enough details about the event discussed. Such an error could be seen as a fundamental attribution error (Myers, 2008), the tendency - when trying to explain the behavior of others (e.g., a child having difficulties to remember) - to overestimate dispositional influence (e.g., the effects of lying), and to underestimate situational influence (e.g., the effects of having to remember an event that took place long ago).

\section{Limitations}

There are a few limitations to the current study. First, from our data we can not tell whether the difference in willingness to answer the unanticipated questions was due to that the liars found themselves in the dilemma we tried to create for them. We simply do not know anything about the mental processes of the liars, and it is for future research to investigate these processes. Second, although the unanticipated questions were selected to be peripheral to all events, some questions could be answered by the use of scripted knowledge (e.g., 'can you remember what you had for breakfast the day that this happened?'), whereas others related less to scripted knowledge (e.g., 'what did you do the day before this happened?'). Any follow-up study should consider this aspect. Third, the time interval between the date of interview and the date of the event discussed differed among the children. We have no reason to believe that this resulted in any systematic differences between the conditions, but we recommend that any follow-up study should take measures controlling for any such possible confound. Fourth, we used one set of anticipated questions and one set of unanticipated questions; future research might profit from using a set where the unanticipated questions are interspersed among anticipated questions.

\section{CONCLUSIONS}

The take home message emerging from the current paper is clear: Truth telling and lying children answered unanticipated questions differently; lying children were more likely to answer them than were truth-telling children. This difference did not emerge when truth-telling and lying children answer anticipated questions and, thus, the willingness to answer unanticipated questions appeared as a diagnostic cue to deception in children. The present study was, however, the first of its kind and we do encourage other researchers to carry out more research in this promising area.

\section{ACKNOWLEDGMENTS}

Thanks to all children who participated in this study.

A portion of this research was presented at the $18^{\text {th }}$ Conference of the European Association of Psychology and Law, Maastricht, July 2008.

\section{APPENDIX}

\section{Anticipated Questions}

1. Can you tell me what happened when... (the interviewer mentions the event that the child is going to talk about)?

2. Can you tell me anything else?

3. Where did this event take place?

4. What did the location, where this happened, look like?

5. How old were you when this happened?

6. What time a day did this happened?

7. What did you think when this happened?

8. Were you alone when this happened?

\section{Unanticipated Questions}

1. Can you tell me what happened when... (the interviewer mentions the event that the child is going to talk about)?

2. Can you tell me anything else?

3. What was the weather like during the day that this happened? 
4. What did you have for breakfast on the day that this happened?

5. What did you do the day before this happened?

6. What kind of shoes were you wearing when this happened?

7. What did you have in your pockets when this happened?

8. What did it smell like at the location where this happened?

\section{REFERENCES}

Crombag, H., Merckelbach, H., \& Elffers, H. (2000). Other people's memory. Psychology, Crime \& Law, 6, 251-265.

DePaulo, B. M. (1992). Nonverbal behavior and self-presentation. Psychological Bulletin, 111, 203-243.

DePaulo, B.M., Lindsay, J.J., Malone, B.E., Muhlenbruck, L., Charlton, K., \& Cooper, H. (2003). Cues to deception. Psychological Bulletin, $129,74-118$

Fiske, S.T., Taylor, S.E. (2008). Social cognition - From brains to culture. Boston: McGraw-Hill Higher Education.

Granhag, P.A., \& Hartwig, M. (2008). A new theoretical perspective on deception detection: On the psychology of instrumental mind reading. Psychology, Crime and Law, 14, 189-200.

Granhag, P.A., \& Strömwall, L.A. (2002). Repeated interrogations: Verbal and non-verbal cues to deception. Applied Cognitive Psychology, 16, 243-257.

Granhag, P.A., \& Vrij, A. (2010). Interviewing to detect deception. In P.A. Granhag (Ed.), Forensic Psychology in Context: Nordic and International Approaches. Cullompton, Devon: Willan Publishing.

Hartwig, M., Granhag, P.A., \& Strömwall, L.A. (2007). Guilty and innocent suspects' strategies during a police interrogation. Psychology, Crime and Law, 13, 213-227.
Kassin, S. M. (2005). On the psychology of confessions: Does innocence put innocents at risk? American Psychologist, 60, 215-228.

Köhnken, G. (2004). Statement validity analysis and the detection of the truth. In P.A. Granhag \& L.A. Strömwall (Eds.), Deception Detection in Forensic Contexts (pp. 41-63). Cambridge, UK: Cambridge University Press.

Lerner, M.J. (1980). The Belief in a Just World: A Fundamental Delusion. New York: Plenum Press.

Myers, D.G. (2008). Social psychology, 9th ed. Boston, MA: McGraw-Hill.

Savitsky, K., \& Gilovich, T. (2003). The illusion of transparency and the alleviation of speech anxiety. Journal of Experimental Social Psychology, 39, 618-625.

Strömwall, L.A., \& Granhag, P.A. (2005). Children's repeated lies and truths: Effects on adult's judgments and reality monitoring scores. Psychiatry, Psychology and Law, 12, 345-356.

Strömwall, L.A., Granhag, P.A., \& Landström, S. (2007). Children's prepared and unprepared lies: Can adults see through their strategies? Applied Cognitive Psychology, 21, 457-471.

Strömwall, L.A., Hartwig, M., \& Granhag, P.A. (2006). To act truthfully: Nonverbal behaviour and strategies during a police interrogation. Psychology, Crime and Law, 12, 207-219.

Vrij, A. (2008). Detecting Lies and Deceit: Pitfalls and Opportunities. $2^{\text {nd }}$ ed. Chichester: John Wiley \& Sons.

Vrij, A., Fisher, R., Mann, S., \& Leal, S. (2006). Detecting deception by manipulating cognitive load. Trends in Cognitive Science, 10, 141142.

Vrij, A., Leal, S., Granhag, P.A., Mann, S., Fisher, R.P., Hillman, J., \& Sperry, K. (2009). Outsmarting the liars: The benefit of asking unanticipated questions. Law and Human Behaviour, 33, 159-66.

Vrij, A., Mann, S.A., Fisher, R.P., Leal, S., Milne, R., \& Bull, R. ( 2008). Increasing cognitive load to facilitate lie detection: The benefit of recalling an event in reverse order. Law and Human Behaviour, 32, 253-65.

Westcott, H.L., Davies, G.M., \& Clifford. B.R. (1991). Adults' perception of children's videotaped truthful and deceptive statements. Children \& Society, 5, 123-135.

(C) Liu et al.; Licensee Bentham Open.

This is an open access article licensed under the terms of the Creative Commons Attribution Non-Commercial License (http://creativecommons.org/licenses/by$\mathrm{nc} / 3.0 /$ ) which permits unrestricted, non-commercial use, distribution and reproduction in any medium, provided the work is properly cited. 